\title{
A Fuzzy Analytical Hierarchy Process for Multiple Equipment Maintenance Decision
}

\author{
Cao Zhen-chong ${ }^{1,2}$, Liu Lian ${ }^{1}$ \\ ${ }^{1}$ School of Electrical Engineering, Wuhan University, Wuhan, China \\ ${ }^{2}$ Guangxi Institute on Exploration and Design of Electric power and Industrial Projects, Naning, \\ China \\ caozhenchong@tsinghua.org.cn
}

Keywords: Triangular fuzzy number (TFN), FAHP, CBM, Electrical equipment

\begin{abstract}
Condition Based Maintenance (CBM) technology is widely used in high-voltage electrical equipment. However, there are complex links between them, what makes the single decision can not meet the requirements of the actual production. This paper presents an improved method - Fuzzy Analytical Hierarchy Process (FAHP), which can deal with the uncertain decision-making factors and vague expertise, based on depth study of AHP. This paper Conducts a comparative analysis of examples and determines the optimal sequencing of the maintenance decision of four transformers with the actual work of a high pressure company. Examples show that the method is suitable for the maintenance of electrical equipment ordering which is affected by a variety of multiple factors.
\end{abstract}

\section{Introduction}

Ower system is developing toward large-capacity, inter-region and automation in order to meet the social progress, economic development and human constant demand. To ensure stable operation of power systems and automation development, the research of condition monitoring and maintenance decision of electrical equipment is imminent.

A single device is established a bese model of maintenance decision before, but now it can not solve the problem in the actual work, so we need to multiple equipment maintenance decision-making models. Multiple equipment maintenance means we need to cosider the links between various devices in maintenance decision to make the best method in the entire system.

However, most of the maintenance optimization model of multiple devices is complex, so it can not meet the needs by modeling a single target. Hence, the fahp based on triangular fuzzy numbers is used in power transformer maintenance decisions with consideration of the impact of more than one power transformer maintenance decisions on the various factors and scientifically deriving optimal multiple decision-making power transformer order.

\section{Triangular Fuzzy Number}

Suppose $\mathrm{A}$ is a fuzzy set in the domain of real numbers $\mathrm{R}$. If $\forall \lambda \in[0,1], A_{\lambda}$ is a finite closed interval in $R, A$ called a fuzzy number in $R$. Suppose $A \in F(R), F(\mathrm{R})$ is all fuzzy set in $R$. Then $A$ is the fuzzy number only if there is a finite closed interval [a,b] in $R$, which must meet the following conditions:

1) $\mu_{A}(x) \equiv 1$ in $[\mathrm{a}, \mathrm{b}]$

2) $\mu_{A}(x)$ is right continuous increasing function. $0 \leq \mu_{A}(x)<1$ in $[-\infty, a]$

3) $\mu_{A}(x)$ is left continuous decreasing function . $0 \leq \mu_{A}(x)<1$ in $[b,+\infty]$

If the membership function $\mu_{A}(x): R \rightarrow[0,1]$ of $\mathrm{A}$ can be expressed as 


$$
\mu_{A}(x)= \begin{cases}\frac{x-l}{m-l} & x \in[l, m] \\ \frac{x-m}{m-u} & x \in[m, u] \\ 0 & \text { others }\end{cases}
$$

Where, $l \leqslant m<u$ and $l, m, u \in R$. Then $A$ is a TFN, which can be written as $(l, m, u) . l$ and $u$ are lower and upper limits of $A . m$ is the median of $A$, which is the most likely value.

The fuzzy numbers insteading of the result between any two factors is fuzzy comparison matrix. If the plot of the symmetry diagonal matrix elements is 1 , it is called fuzzy reciprocal comparison matrix. Suppose $A=\left(a_{i j}\right)_{n \times n}$ is a fuzzy reciprocal comparison matrix and $a_{i j}$ is a triangular Fuzzy Number, $A$ is called Triangular fuzzy reciprocal comparison matrix.

If $A=\left(a_{i j}\right)_{n \times n}$ is a positive triangular fuzzy reciprocal comparison matrix, $a_{i j}=\left(l_{i j}, m_{i j}, u_{i j}\right), i, j=1,2, \ldots, n$, and $\bar{A}=\left(m_{i j}\right)_{n \times n}$ is a consistency comparison matrix, then $A=\left(a_{i j}\right)_{n \times n}$ is also a consistency comparison matrix.

Suppose $\alpha_{k}$ is a Weight coefficient, the solving formula of the weight vector for Triangular fuzzy comparison matrix is

$$
\begin{aligned}
& \alpha_{k}=\sum_{j=1}^{n} a_{i j} \cdot\left(\sum_{i=1}^{n} \sum_{j=1}^{n} a_{i j}\right)^{-1} \\
& \text { Or } \\
& \alpha_{k}=\left(\frac{\sum_{j=1}^{n} l_{i j}}{\sum_{i=1}^{n} \sum_{j=1}^{n} u_{i j}}, \frac{\sum_{j=1}^{n} m_{i j}}{\sum_{i=1}^{n} \sum_{j=1}^{n} m_{i j}}, \frac{\sum_{j=1}^{n} u_{i j}}{\sum_{i=1}^{n} \sum_{j=1}^{n} l_{i j}}\right)
\end{aligned}
$$

\section{Sorting method of TFN based on Improved Possibility}

There are many triangular fuzzy number sort methods, which are mainly based on the possibility theory, the $\alpha$ cutset theory ,the thought of membership function of triangular fuzzy, the distance formula, and so on. This article employs the sort method which is based on be compared possibility.

Suppose ${ }^{M_{1}}$ and $M_{2}$ is triangular fuzzy numbers of R, and

$V\left(M_{1} \geq M_{2}\right)=\sup _{x \geq y}\left(\min \left(\mu_{M_{1}}(x), \mu_{M_{2}}(y)\right)\right)$

$V\left(M_{1} \geq M_{2}\right)$ is called the possibility of $M_{1} \geq M_{2}$.

Suppose $M_{1}=\left(l_{1}, m_{1}, u_{1}\right), M_{2}=\left(l_{2}, m_{2}, u_{2}\right)$,then

$$
V\left(M_{1} \geq M_{2}\right)= \begin{cases}1 & m_{1} \geq m_{2} \\ \frac{u_{1}-l_{2}}{\left(u_{1}-m_{1}\right)+\left(m_{2}-l_{2}\right)} & m_{1}<m_{2}, u_{1}>l_{2} \\ 0 & u_{1} \leq l_{2}\end{cases}
$$

Supppose $s=\left[s_{1}, s_{2}, \ldots, s_{Q}\right]$ is a comprehensive weight vector, we calculate the possibility $V\left(s_{i} \geq s_{j}\right)$ of $s_{i} \geq s_{j}$ and the possibility $d(q)=\min _{i \neq j}\left\{V\left(s_{i} \geq s_{j}\right)\right\} \quad i, j, q \in Q$ 且 $j \neq i$ ) which may be superior to all other programs. Then we can get ranking vectors of each program after making a unitary processing for $d(q)$.This method is simple in theory, but there are shortcomings, containing contradictions compared with the triangular fuzzy number of people's conventional thinking. For example, $a_{1}=[3,3,6], a_{2}=[1,4,4]$, according to the described above method, $V\left(a_{2} \geq a_{1}\right)=1$. 
This paper proposes a method of compared-possibility and averages dominance. Suppose $N_{1}$ and $N_{2}$ is any triangular fuzzy numbers, the averages dominance of $N_{1} \geq N_{2}$ is

$P\left(N_{1} \geq N_{2}\right)=\frac{V\left(N_{1} \geq N_{2}\right)+1-V\left(N_{2} \geq N_{1}\right)}{2}$

The above definition is the same as the fuzzy reciproca matrix.

If

$r_{i j}=P\left(N_{i} \geq N_{j}\right), i, j=1,2, \ldots, n$

$R=\left(r_{i j}\right)_{n \times n}$ is a fuzzy reciproca matrix.

By the defined average dominance of two triangular fuzzy numbers above, we successfully transform the question of triangular fuzzy number reciprocal Judgement Matrix is into fuzzy complementary matrix. Then we can calculate fuzzy comprehensive weight by related methods of fuzzy related matrix.

\section{Steps of FAHP based on TFN}

1) Determine the hierarchical structure: the top target work out optimal decision scheme is for state overhaul of many sets of transformer, intermediate layer analysis the factors which effects the ultimate goal and the solution layer is presented for the ultimate goal.

2) While the experts score in the form of triangular fuzzy numbers, the factor fuzzy judgment matrix and fuzzy judgment matrix is determined according to experts and comparison of two scoring results. hypothesis that the factor judgment matrix is $C=\left(c_{i j}\right)_{n \times n}, c_{i j}=\left(l_{i j}^{c}, m_{i j}^{c}, u_{i j}^{c}\right)$ and the fuzzy judgment matrix is $P=\left(p_{i j}\right)_{n \times n}, p_{i j}=\left(l_{i j}^{p}, m_{i j}^{p}, u_{i j}^{p}\right)$.

3) Test the single criterion of fuzzy judgment matrix consistency and calculate the weight vector of the corresponding matrix. Then matrix weight calculation formula for the factor judgment is

$$
S_{k}=\sum_{j=1}^{n} c_{i j} \cdot\left(\sum_{i=1}^{n} \sum_{j=1}^{n} c_{i j}\right)^{-1}
$$

It can also be written as

$$
S_{k}=\left(\frac{\sum_{j=1}^{n} l_{i j}^{c}}{\sum_{i=1}^{n} \sum_{j=1}^{n} u_{i j}^{c}}, \frac{\sum_{j=1}^{n} m_{i j}^{c}}{\sum_{i=1}^{n} \sum_{j=1}^{n} m_{i j}^{c}}, \frac{\sum_{j=1}^{n} u_{i j}^{c}}{\sum_{i=1}^{n} \sum_{j=1}^{n} l_{i j}^{c}}\right)
$$

Assuming $S_{k}$ as the Local factor weight, the local factors weight vector is $S=\left[S_{1}, S_{2}, \ldots, S_{n}\right]$.

Programme for the judgment matrix weight calculation formula $F_{k q}=\sum_{j=1}^{Q} p_{i j} \cdot\left(\sum_{i=1}^{Q} \sum_{j=1}^{Q} p_{i j}\right)^{-1}$

It can also be written as

$$
F_{k q}=\left(\frac{\sum_{j=1}^{Q} l_{i j}^{p}}{\sum_{i=1}^{Q} \sum_{j=1}^{Q} u_{i j}^{p}}, \frac{\sum_{j=1}^{Q} m_{i j}^{p}}{\sum_{i=1}^{Q} \sum_{j=1}^{Q} m_{i j}^{p}}, \frac{\sum_{j=1}^{Q} u_{i j}^{p}}{\sum_{i=1}^{Q} \sum_{j=1}^{Q} l_{i j}^{p}}\right)
$$

The localscheme weight matrix can be represented as $F=\left[F_{k q}\right]_{n \times Q}$. Then, the formula for the local weighting vector is

$$
J=S \times F
$$

4) According to the local weight vector ,work out the comprehensive weight on the ultimate goal of each scheme .Assuming that the comprehensive weight vector is $Z=\left[Z_{1}, Z_{2}, \ldots, Z_{Q}\right]$, calculate the possible degree of $Z_{i} \geq Z_{j}$, that is to say $V\left(Z_{i} \geq Z_{j}\right)$, $(i, j, q \in Q$ 且 $j \neq i$ ). Then making use of an 
improved possibility degree method -- comparison of average dominance, work out the average dominance of Comprehensive weight vectors and establish a comparison information matrix which represents the compared plans, this matrix is fuzzy complementary matrix. At last, sort the fuzzy complementary matrix. The larger the sorting values, the sronger the corresponding solutions relative advantage .So the decision makers can choose the maximum one as the optimal scheme.

\section{Case Study}

There are four transformers, called a, b, c and d, in a Ultra-high-pressure company. Figure 1 shows that the optimal maintenance order hierarchical model of these transformers.

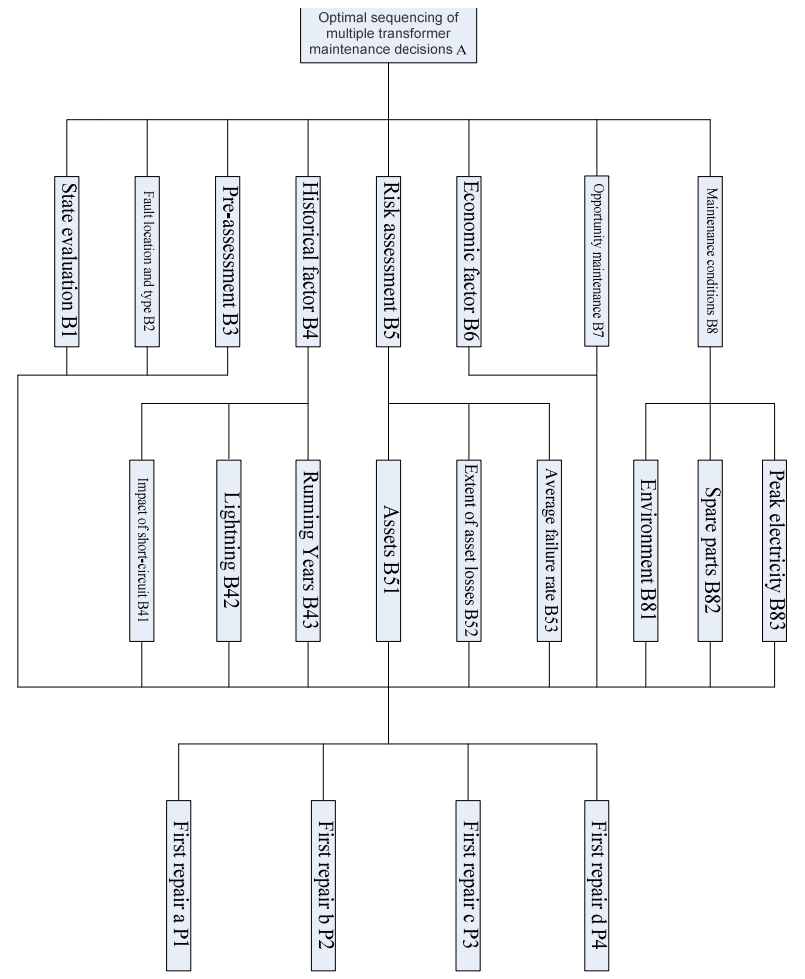

Figure 1.Optimal maintenance order hierarchical model of transformers

Table I shows the factors that affect transformers decision

Table I.Factors that affect optimal maintenance decision

\begin{tabular}{|c|c|c|c|c|c|c|}
\hline $\begin{array}{l}\text { Target } \\
\text { layer }\end{array}$ & \multicolumn{2}{|c|}{ Criterion layer } & Transformer a & Transformer b & Transformer c & Transformer $\mathrm{d}$ \\
\hline \multirow{13}{*}{$\begin{array}{l}\text { Optima } \\
\text { l } \\
\text { mainte } \\
\text { nance } \\
\text { order } \\
\text { of } \\
\text { transfo } \\
\text { rmers }\end{array}$} & \multicolumn{2}{|c|}{ State evaluation } & Single Attention & abnormal & abnormal & serious \\
\hline & \multicolumn{2}{|c|}{ Fault location and type } & $\begin{array}{l}\text { mechanical failure } \\
\text { A }\end{array}$ & $\begin{array}{l}\text { Thermal fault } \\
\text { A }\end{array}$ & Trimble fault B & $\begin{array}{l}\text { Thermal fault } \\
\text { A }\end{array}$ \\
\hline & \multicolumn{2}{|c|}{ Pre-assessment } & 10 months & 6 months & 5 months & 1 months \\
\hline & \multirow{3}{*}{$\begin{array}{l}\text { Historical } \\
\text { factor }\end{array}$} & $\begin{array}{l}\text { Impact of } \\
\text { short-circuit }\end{array}$ & General & Good & well & great \\
\hline & & Lightning & $\mathrm{n}=0$ & $\mathrm{n}=1$ & $\mathrm{n}=0$ & $n=2$ \\
\hline & & Running Years & 5 & 7 & 18 & 9 \\
\hline & \multirow{2}{*}{$\begin{array}{l}\text { Risk } \\
\text { assessment }\end{array}$} & Assets & 9 & 7.4 & 7.4 & 4.9 \\
\hline & & $\begin{array}{l}\text { Average failure } \\
\text { rate }\end{array}$ & General & Good & well & great \\
\hline & \multicolumn{2}{|c|}{ Economic factor } & Significantly important & Very important & Very important & important \\
\hline & \multicolumn{2}{|c|}{ Opportunity maintenance } & no & no & yes & yes \\
\hline & \multirow{3}{*}{$\begin{array}{l}\text { Maintenanc } \\
\text { e conditions }\end{array}$} & Environment & no & no & no & yes \\
\hline & & Spare parts & yes & yes & no & no \\
\hline & & Peak electricity & no & yes & no & no \\
\hline
\end{tabular}

Constructing comparison determine matrix of factors and formula 
1) The constructing comparison determine matrix of factors based on figure 1:

Table II. Constructing comparison determine matrix of factors

\begin{tabular}{|l|l|l|l|}
\hline No. & name & order & meaning \\
\hline 1 & $M^{A}$ & 8 & $\begin{array}{l}\text { Pairwise comparison of } \\
\text { the second layer } \\
\text { sub-factors to the } \\
\text { overall target layer }\end{array}$ \\
\hline 2 & $M^{B 4}$ & 3 & $\begin{array}{l}\text { Pairwise comparison of } \\
\text { B4 to B4 }\end{array}$ \\
\hline 3 & $M^{B 5}$ & 3 & comparison of B5 to B5 \\
\hline 4 & $M^{B 8}$ & 3 & comparison of B8 to B8 \\
\hline
\end{tabular}

2) Weight of the factor matrixs

Table III.Factor weight vector

\begin{tabular}{|l|l|}
\hline name & Weight vector corresponding to factors \\
\hline$M^{B 4}$ & {$[(0.2857,0.4286,0.6316)(0.2857,0.4286,0.6316)(0.1071,0.1429,0.2105)]$} \\
\hline$M^{B 5}$ & {$[(0.2857,0.4286,0.6316)(0.2857,0.4286,0.6316)(0.1071,0.1429,0.2105)]$} \\
\hline$M^{B 8}$ & {$[(0.2308,0.5000,0.9130)(0.1795,0.2500,0.3913)(0.1795,0.2500,0.3913)]$} \\
\hline
\end{tabular}

3) Integrated multiple expert opinion, we can draw a comparison determine matrix of B1-B8 and test the consistency, and determine the formula -factor-weight of these matrixs. Then we can determine the weight of all of the factors to options. This is the formula - weight matrixs:

$\left[\begin{array}{llll}(0.0380,0.0462,0.0588) & (0.1477,0.2073,0.2848) & (0.2685,0.3732,0.5201) & (0.2685,0.3732,0.5201) \\ (0.2975,0.4891,0.7826) & (0.1405,0.2174,0.3391) & (0.0551,0.0761,0.1174) & (0.1405,0.2174,0.3391) \\ (0.2045,0.2982,0.4324) & (0.1382,0.1936,0.2744) & (0.0327,0.0402,0.0515) & (0.3271,0.4680,0.6652) \\ (0.0401,0.0796,0.1728) & (0.0848,0.2172,0.5468) & (0.1147,0.2573,0.6079) & (0.1821,0.4460,1.0591) \\ (0.1627,0.3186,0.6324) & (0.1266,0.2270,0.4208) & (0.1374,0.2487,0.4688) & (0.1213,0.2058,0.3701) \\ (0.2975,0.4891,0.7826) & (0.1405,0.2174,0.3391) & (0.1405,0.2174,0.3391) & (0.0551,0.0761,0.1174) \\ (0.0707,0.0833,0.1014) & (0.0707,0.0833,0.1014) & (0.3030,0.4167,0.5676) & (0.3030,0.4167,0.5676) \\ (0.1071,0.2715,0.6598) & (0.1541,0.3786,0.9127) & (0.0631,0.1215,0.2502) & (0.1100,0.2286,0.5030)\end{array}\right]$

\section{Comprehensive weight}

We can calculate the weight factor $S^{A}$ based on factors-comparison matrix $M^{A}$ of all of the factors to overall target factor, and obtaine weights from the bottom layer by layer based on FAHP, and then calculate the comprehensive weight $\mathrm{N}$ of four formulas to overall target. $N=S^{A} \times N^{B}$

$$
\mathrm{N}=\left[\begin{array}{l}
(0.0558,0.1415,0.3740) \\
(0.1094,0.2545,0.6197) \\
(0.0924,0.2147,0.5274) \\
(0.1665,0.3894,0.9313)
\end{array}\right]
$$

\section{Optimal decision-making formula}

Comparing four triangular fuzzy numbers, we draw a dominance matrix based on Comprehensive weight that is calculated.

$$
\mathrm{V}=\left[\begin{array}{cccc}
1 & 0.7007 & 0.7937 & 0.4556 \\
1 & 1 & 1 & 0.7568 \\
1 & 0.9131 & 1 & 0.6738 \\
1 & 1 & 1 & 1
\end{array}\right]
$$

Transforming fuzzy numbers-determine matrix into Fuzzy Complementary Judgement Matrix, we draw a mean dominance matrix or so-called Fuzzy Complementary Judgement Matrix R

$$
R=\left[\begin{array}{cccc}
0.5 & 0.3504 & 0.3968 & 0.2278 \\
0.6496 & 0.5 & 0.5435 & 0.3853 \\
0.6032 & 0.4565 & 0.5 & 0.3369 \\
0.7722 & 0.6147 & 0.6631 & 0.5
\end{array}\right]
$$

Since ordering vector of the average dominance matrix is one correspondence to synthesis weights, we know the famula sort Correspond to the Sort vector of matrix R . Calculating the matrix R, we can slove vector of matrix $\mathrm{R}$, which means the order of the corresponding famula is drawn

$w=(0.1188,0.2696,0.2241,0.3875)$

According to the above results, $w_{4}>w_{2}>w_{3}>w_{1}$, The final integrated decision-making famula is repairing d firstly, b secondly, c thirdly, and a finally. 


\section{Conclusion}

Through a comparative analysis of cases of multiple transformer maintenance decision-making order to the state-based, integrated decision-making with a variety of factors to arrive at optimal decisions order more scientific. Compared to traditional manual methods, the FAHP based on Triangular fuzzy numbers can give the more scientifically optimal sequencing of the multiple transformer maintenance decision, which has a certain application.

\section{References}

[1] PJM.Laarhoven and W.pedyrez. A fuzzy extention of saaty’s priority theory. Fuzzy Sets and Systems.1983,11:229-241.

[2] J.J.Buckly, T.Feuring, Y.Hayashi. Fuzzy hierarchical analysis revisited. European Journal of Operational Research [J].129(2001):48-64.

[3] L.C.Leung,D.Cao. On consistency and ranking of alternatives in fuzzy AHP. European Journal of Operational Research [J].2000,(124):102-113..

[4] D.Y.Chang. Applications of the Extent Analysis Method on Fuzzy AHP. European Journal of Operational Research [J].1996,95(3):649-655.

[5] X.Dong,Z.Wang,A.Kahtib,B.Qiu,Y.Liu Internet Based Fault Diagnosis for Power Transformers. IEEE PES Summer Meeting proceedings,Seattle,July 2000,6

[6] X.Dong,Y.Liu,et al. Internet Applications in Condition Monitoring of Power Equipment. the first International Conference on Insulation Condition Monitoring of Electrical Plants, Wuhan, China, Sept.2000,10 pages

[7] X.Ding,E.Yao,Y.Liu,P.Griffin. ANN Based Analysis of Transformer Failures Using Gas-in-oil Data. Proceedings of The 55th American Power Conference, Chicago,IL,April 1993,5 pages

[8] X.Ding,Y.Liu, An Artificial Neural Network Approach to Transformer Fault Diagnosis. Automation of Electric Power Systems(magazine),Jan.1996,pp.27-32,6 pages

[9] Zhenyuan Wang,Nien-chung Wang,Tzong-Yih Guo,Frank T.C.Huang, Yilu-Liu,Paul J. Griffin. Artificial Intelligence in Power Equipment Fault Diagnosis. IEEE PES Winter Meeting Proceedings,Singapore,Feb.2000,6 pages

[10]Yang JB,XuDL. Nonlinear information aggregation via evidential reasoning in multi-attribute decision analysis under uncertainty[J]. IEEE Transactions on systems, Man and cybernetics, PartA, 2002,32(3):376-393.

[11]Dong-Ling Xu,Jian-Bo Yang. The evidential reasoning approach for multi-attribute decision analysis under interval uncertainty[J].European Journal of operational Research,2006,174(3): 1914-1943. 